\title{
NOTES: transvaginal cholecystectomy with assisting articulating instruments
}

\author{
Santiago Horgan · Yoav Mintz · Garth R. Jacobsen • Bryan J. Sandler • \\ John P. Cullen · Adam Spivack · David W. Easter · Alana Chock · \\ Michelle K. Savu · Sonia Ramamoorthy · Julie Bosia - Sanjay Agarwal · \\ Emily Lukacz $\cdot$ Emily Whitcomb $\cdot$ Thomas Savides $\cdot$ Mark A. Talamini
}

Received: 2 October 2008/Accepted: 13 March 2009/Published online: 9 May 2009

(c) The Author(s) 2009. This article is published with open access at Springerlink.com

\begin{abstract}
Background Transvaginal cholecystectomy has been performed at several institutions using hybrid natural orifice translumenal endoscopic surgery (NOTES) techniques. Methods A 42-year-old woman with symptomatic cholelithiasis was taken to the operating room for transvaginal cholecystectomy after giving informed consent. A single 5-mm laparoscope was placed at the umbilicus, followed by a $15-\mathrm{mm}$ trocar through the vaginal conduit. The endoscope and a long flexible RealHand surgical instrument (Novare, Cupertino, CA) were placed via the vaginal trocar. The cystic duct and artery were identified and clipped using laparoscopic clips from the umbilical port. The long articulating laparoscopic instrument provided stable retraction. Hook cautery was used to dissect the gallbladder, which was removed via the vaginal trocar. The vaginal incision was closed using a single figure-of-eight absorbable suture under direct vision. The procedure lasted $96 \mathrm{~min}$.
\end{abstract}

Electronic supplementary material The online version of this article (doi:10.1007/s00464-009-0471-x) contains supplementary material, which is available to authorized users.

S. Horgan · Y. Mintz - G. R. Jacobsen ·

B. J. Sandler · J. P. Cullen · A. Spivack $(\varangle)$.

D. W. Easter - A. Chock - M. K. Savu - S. Ramamoorthy

J. Bosia - S. Agarwal - E. Lukacz - E. Whitcomb - T. Savides ·

M. A. Talamini

University of California San Diego, San Diego, USA

e-mail: aspivack@ucsd.edu
Results The cholecystectomy was successfully performed without spillage of bile. The patient was kept overnight for observation only as a precaution. She reported no pain and did not require a discharge prescription for narcotics.

Conclusions The described technique for NOTES cholecystectomy results in a virtually scarless operation. The single 5-mm umbilical trocar allows for safe clipping of the cystic duct. Further work is needed to determine the efficacy of this approach.

Keywords Articulating grasper - Cholecystectomy · New technology $\cdot$ NOTES $\cdot$ Transvaginal

Open Access This article is distributed under the terms of the Creative Commons Attribution Noncommercial License which permits any noncommercial use, distribution, and reproduction in any medium, provided the original author(s) and source are credited. 